\title{
Detection of Non-Traumatic Knee Effusion among Asymptomatic Individual with Different type of Lifestyle and Selected Sociodemographic Factors Using Fluid Shift Test and Ultrasonography
}

\author{
Myint Swe ${ }^{1 *}$, Ramani Subramanium ${ }^{2}$, Sabridah Ismail ${ }^{3}$ and Biju Benjamin ${ }^{4}$ \\ ${ }^{1}$ Department of Orthopaedics, Royal College of Medicine Perak, University Kuala Lumpur, Malaysia \\ ${ }^{2}$ Department of Radiology, Royal College of Medicine Perak, University Kuala Lumpur, Malaysia \\ ${ }^{3}$ Department of Public Health, Royal College of Medicine Perak, University Kuala Lumpur, Malaysia \\ ${ }^{4}$ Department of Orthopaedics and Trauma surgery, University College London Hospital, 235, Euston Road, London, UK
}

"Corresponding author: Myint Swe, Associate professor, Royal College of Medicine Perak Orthopaedic unit, Surgical based department, 28, Lebuh Sungai Senam, Taman Ipoh, Perak 31400, Malaysia, Tel: +60163445106; +6052432635; Fax: 6052536637; E-mail: drmsconortho@gmail.com

Received date: March 21, 2018; Accepted date: April 05, 2018; Published date: April 09, 2018

Copyright: ( 2018 Swe M, et al. This is an open-access article distributed under the terms of the Creative Commons Attribution License, which permits unrestricted use, distribution, and reproduction in any medium, provided the original author and source are credited.

\begin{abstract}
Background history: Non-traumatic knee effusion might be the result of overuse leading to wear and tear processes or systemic diseases. Knee effusion-synovitis was a predictive of some structural abnormalities in the joint suggesting a potential role in early osteoarthritis changes. It is postulated that the active life style with prolonged standing hours predisposed for the increase prevalence of non-traumatic knee effusion even in the young age.
\end{abstract}

Method: Final year medical students and clerical office staffs from Royal college of Medicine Perak were randomly selected. Those who had some kind of physical activities (walking, jogging or any kind of sports) for more than half an hour a day at least three times per week among the students and the clerical office staffs were included in active life style group and the remaining were listed in sedentary life style group. All were assessed for knee effusion by two orthopaedic surgeons clinically and then assessed by ultrasound examination on the same day. All were less than 30 years of age.

Results: Data from 46 staffs and 53 students (total 99) were analysed. Number of participants in active life style group was 72 and that in sedentary life style groups was 27 . Among the 99 participants, $53(53.53 \%)$ had positive fluid shift test and 46 (46.5\%) had effusion on ultrasound examination.

The respondents who practice active lifestyle and respondents with BMI more than 25 had more prevalence than non-active respondents and respondents with BMI less than 25 respectively.

Conclusion: The persons with active life style had more chance of having knee effusion. The five-point scale method of fluid shift test or stroke test is a reliable test for detection of small amounts of fluid in knee.

Keywords: Effusion; Knee; Ultrasound; Fluid shift test; Active; Sedentary; Lifestyle

\section{Introduction}

There is a certain amount of synovial fluid inside any synovial joint especially in large joints such as knee joint. The presence of normal amount of synovial fluid can't be detected by clinical examination as well as by ultrasonography but can be detected by MRI and it is termed as effusion-synovitis [1]. The minimal amount of fluid in the knee to be detected by ultrasonography is $4.13+0.17 \mathrm{ml}$ [2].

As a response to the movement of the joint, synovial fluid is secreted by type B cells of synovial membrane. Synovial fluid moves into the cartilage when a joint is resting, and moves out into the joint space when the joint is active, particularly when weight-bearing. Synovial fluid includes hyaluronic acid (HA), lubricin (PRG4), surface-active phospholipids (SAPL), proteinases, and collagenases [3]. Type A is phagocytic cells which removes the wear-and-tear debris from the synovial fluid. HA and PRG4 increase the viscosity and elasticity of articular cartilages and lubricate the surfaces between synovium and cartilage.

Knee effusion can be classified into traumatic and non-traumatic. Non-traumatic aetiologies include degenerative arthritis, inflammatory arthritis, infection, crystal deposition and tumour [4]. There is obvious reason for knee effusion in cases of inflammatory, infectious, crystal deposition diseases and tumour cases. The most common reasons for degenerative arthritis are overuse, repetitive stress and active life style. But the exact cause of primary osteoarthritis is still under question. There is decrease in concentration of HA and SAPL in synovial fluid of primary osteoarthritic patients by the unknown mechanism [5]. Osmolarity of synovial fluid regulates chondrogenic differentiation potential of synovial fluid derived mesenchymal progenitor cells for repair of damaged articular cartilage [6]. In young age there is a balance between wear and tear and repair. In old age, repair process can't compensate the wear and tear resulting in progressive damage to 
Citation: Swe M, Subramanium R, Ismail S, Benjamin B (2018) Detection of Non-Traumatic Knee Effusion among Asymptomatic Individual with Different type of Lifestyle and Selected Sociodemographic Factors Using Fluid Shift Test and Ultrasonography. J Arthritis 7: 270. doi: $10.4172 / 2167-7921.1000270$

Page 2 of 5

cartilage. Therefore effusion of joints were more common in old age due to degenerative arthritis compare to the younger one. However young persons can have early osteoarthritis as a result of overload or over use. According to a 2007 National Health Surveillance Survey in Singapore, about 10 per cent of residents between the ages of 18 and 69 had arthritis and chronic joint symptoms. A study conducted by Dr. Kevin Lee showed that those who run more than $10 \mathrm{~km}$ a week were two times more prone to be afflicted with lower limb injuries than those who run shorter distances [7].

It had been observed that fluid shift test was positive in most of the asymptomatic final year medical students who volunteered to be simulated patients during teaching sessions. It was postulated that the active life style of medical students with prolonged standing hours predisposes for non-traumatic knee effusion which might be an early sign of osteoarthritis.

Knee effusion is a common finding in patients with knee problems although patients may or may not noticed that his/her knee is swollen up. The clinical tests for detection of knee effusion routinely used at present time are patella tap test, cross fluctuation test and fluid shift test. The present of knee effusion can be confirmed by ultrasonography, MRI, circumferential measurements using a measuring tape comparing the size of both knees and volumetry using water displacement as a mean to assess limb volume [8]. Patella tap and cross fluctuation tests can only detect moderate or large amount of knee effusion. For detection of small amount of knee effusion, fluid shift test or stroke test is used. It is also called Brush test, Sweep test or Wipe Test.

The fluid shift test is performed in supine position of patient with the knee in full extension and relaxed [8]. Some prefers to conduct the examination either in 30 degree knee flexed position or in sitting position. This test is performed by stroking proximally with the fingers on the medial side of knee from below upwards up to the suprapatellar pouch two or three times. Then stroking down with other hand is done on the lateral side of the patella [8]. Wave of fluid passes to the medial side of the joint and bulges is seen medial to the patella tendon within few seconds. Effusion of the knee joint is recorded using a 5-point scale (Table 1) [8-13].

\begin{tabular}{|l|l|}
\hline Grade & Test results \\
\hline 0 & No wave produced on down stroke \\
\hline Trace & Small wave on medial side with down stroke \\
\hline $1+$ & Larger bulge on medial side with down stroke \\
\hline $2+$ & $\begin{array}{l}\text { Effusion spontaneously returns to medial side after upstroke (no down } \\
\text { stroke necessary) }\end{array}$ \\
\hline $3+$ & $\begin{array}{l}\text { So much fluid that it is not possible to move the effusion out of the } \\
\text { medial aspect of the knee }\end{array}$ \\
\hline
\end{tabular}

Table 1: Test results.

The aims of this study:

1- To determine the prevalence of non-traumatic knee effusion among active young adult.

2- To compare the prevalence of non-traumatic knee effusion among active lifestyle with sedentary lifestyle, age, gender, staffs and medical student and BMI status.
3- To differentiate the finding on detecting knee effusion using fluid test and ultrasonography.

\section{Methodology}

This is a study on the prevalence of non-traumatic knee effusion among medical students and clerical staffs from Royal College of Medicine Perak.

The study was announced to both groups. The students or staffs who were attending to the study center on the specific time and date were assessed for the eligibility.

If the respondents eligible, they were asked to give consent before the study proceeded.

The data were collected through two ways:

Face to face interview to collect respondents' socio-demography such as age, gender, working status and their lifestyle.

The active life style was referred to respondents who gave the history of performing any activities (walking, jogging, exercise at gymnasium, any sports such as badminton, table tennis, futsal) more than half hour per day at least three times per week.

Measurements were height, weight to calculate BMI, fluid shift test and ultrasound.

The measuring equipment was calibrated after every 5 respondents. Each measurement was taken 2 or 3 times till the reading became consistent.

Fluid shift test was done by two Orthopaedic surgeons using a 5point scale method successively in separate room and recorded separately.

The ultrasound scanning done by dedicated radiologist using Prosound alpha 6 ultrasound machine with high frequency probe model UST -5413 from Hitachi Aloka Medical Limited. The ultrasonographic examinations were done in 30 degree flexed position of knee.

The machine was choosing because of its capability to detect the presence of fluid in the knee as lower as $4.13+0.17 \mathrm{ml}$ instead of standard minimum of $5 \mathrm{ml}$ [2]. Therefore once fluid was detected by ultrasonogrphy it was diagnosed as more than normal (Figure 1).

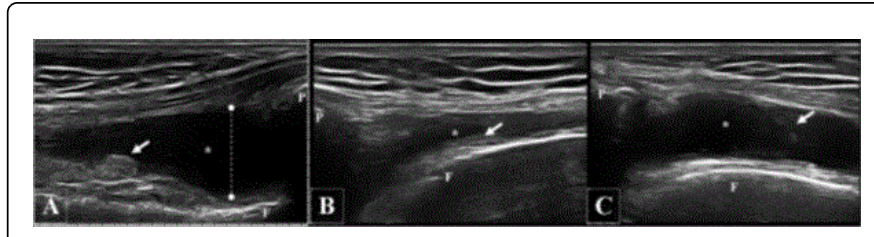

Figure 1: Sonographic examination of major recesses of the knee: A, suprapatellar recess, sagittal plane; B, medial parapatella recess, mid-patella transverse plane; and $\mathrm{C}$, lateral parapatella recess, midpatella transverse plane. *effusion; $\mathrm{F}_{\text {_ }}$ femur; $\mathrm{P}_{\text {_ }}$ patella; arrow synovial hypertrophy; dotted line _ measurement of greatest diameter of fluid.

\section{Inclusion criteria}

- All final year students who gave consent 
Citation: Swe M, Subramanium R, Ismail S, Benjamin B (2018) Detection of Non-Traumatic Knee Effusion among Asymptomatic Individual with Different type of Lifestyle and Selected Sociodemographic Factors Using Fluid Shift Test and Ultrasonography. J Arthritis 7: 270. doi: $10.4172 / 2167-7921.1000270$

Page 3 of 5

- Clerical staff from university under 30 years of age

- Those who came to the study center on the specific day and time.

- Agreed to participate into the study.

\section{Exclusion criteria}

- Those with history of knee injury, any knee problems or knee operation.

- Age more than 30 years old

- Those who didn’t give consent

\section{Data Analysis}

Data were cleaned and entered in SPSS software version 17 (student's version).

The age was categorized to less than 25 and equal and more than 25 years old. Gender was male and female whereas the job status was classified into student and staffs. BMI were calculated and later on had been classified into BMI less than 25 and equal and more than 25 .

The lifestyle was categorized into active and non-active.

Hypothesis testing used was Chi square (ordinary and 3 level). The significant value was less than 0.05 .

Inter-rater reliability for fluid shift test between two orthopaedic surgeons was also calculated.

\section{Result}

Total number of eligible respondents was 99.

$50.5 \%$ were in age group less than 25 years old.

$54.5 \%$ were male and $45.5 \%$ were female.

$53.5 \%$ were students and $46.5 \%$ were staffs

$72.7 \%$ were in active category and $60.6 \%$ with BMI less than 25 (Table 2).

\begin{tabular}{|c|c|c|c|}
\hline & Variable & Number & Percentage (\%) \\
\hline \multirow[t]{3}{*}{1} & \multicolumn{3}{|l|}{ Age group } \\
\hline & $<25$ years old & 50 & 50.5 \\
\hline & $\geq 25$ & 49 & 49.5 \\
\hline \multirow[t]{3}{*}{2} & \multicolumn{3}{|l|}{ Gender } \\
\hline & Male & 54 & 54.5 \\
\hline & Female & 45 & 45.5 \\
\hline \multirow[t]{3}{*}{3} & \multicolumn{3}{|l|}{ Status } \\
\hline & Staff & 46 & 46.5 \\
\hline & Student & 53 & 53.5 \\
\hline \multirow[t]{3}{*}{4} & \multicolumn{3}{|l|}{ Lifestyle } \\
\hline & Not active & 27 & 27.3 \\
\hline & Active & 72 & 72.7 \\
\hline
\end{tabular}

\begin{tabular}{|l|l|l|l|}
\hline \multirow{5}{*}{5} & \multicolumn{3}{|l|}{ BMI category } \\
\cline { 2 - 4 } & $<25$ & 60 & 60.6 \\
\cline { 2 - 4 } & $\geq 25$ & 39 & 39.4 \\
\hline
\end{tabular}

Table 2: Distribution of respondents according to age category, gender, status, lifestyle and BMI category.

Inter-rater reliability for fluid shift test was $79.25 \%$ as positive cases by surgeon 1 was 53 and surgeon 2 was 42 . But higher score was used for analysis.

$53.53 \%$ (53) of respondents were detected positive knee effusion by fluid shift test (Table 3 ).

\begin{tabular}{|c|c|c|c|c|}
\hline & \multirow[t]{2}{*}{ Variable } & \multirow{2}{*}{$\begin{array}{l}\text { Fluid shift test } \\
\text { negative } \\
\text { Number }(\%) \\
\text { Total } 46(46.46 \%)\end{array}$} & Number (\%) & \multirow[t]{2}{*}{$P$ value } \\
\hline & & & $\begin{array}{ll}\text { Total } & 53 \\
(53.53 \%) & \end{array}$ & \\
\hline \multirow[t]{3}{*}{1} & \multicolumn{2}{|l|}{ Age group } & & \\
\hline & $<25$ years old & $18(36.0 \%)$ & $32(64.0 \%)$ & \multirow[t]{2}{*}{$0.003^{*}$} \\
\hline & $\geq 25$ & $28(57.1 \%)$ & $21(42.9 \%)$ & \\
\hline \multirow[t]{3}{*}{2} & \multicolumn{4}{|l|}{ Gender } \\
\hline & Male & $22(40.7 \%)$ & $32(59.3 \%)$ & \multirow[t]{2}{*}{$0.045^{\star}$} \\
\hline & Female & $24(53.3 \%)$ & $21(46.7 \%)$ & \\
\hline \multirow[t]{3}{*}{3} & \multicolumn{4}{|l|}{ Status } \\
\hline & Staff & $32(69.6 \%)$ & $14(30.4 \%)$ & \multirow[t]{2}{*}{$0.000^{*}$} \\
\hline & Student & $14(26.4 \%)$ & $39(73.6 \%)$ & \\
\hline \multirow[t]{3}{*}{4} & \multicolumn{4}{|l|}{ Lifestyle } \\
\hline & Not active & $18(66.7 \%)$ & $9(33.3 \%)$ & \multirow[t]{2}{*}{$0.003^{*}$} \\
\hline & Active & $28(38.9 \%)$ & $44(61.1 \%)$ & \\
\hline \multirow[t]{3}{*}{5} & \multicolumn{4}{|l|}{ BMI category } \\
\hline & $<25$ & $24(40 \%)$ & $36(60 \%)$ & \multirow[t]{2}{*}{$0.023^{*}$} \\
\hline & $\geq 25$ & $22(56.4 \%)$ & $17(43.6 \%)$ & \\
\hline
\end{tabular}

Table 3: The association between demographic variables and fluid shift test for knee effusion.

$46.5 \%$ (46) of respondents were detected positive knee effusion by ultrasound (Table 4).

$64 \%$ of age below 25 years old were positive for knee effusion by Fluid shift test whereas only $42.9 \%$ of above 25 year old were positive (Table 3).

$46 \%$ of age below 25 years old had positive knee effusion by ultrasound whereas $46.9 \%$ of above 25 year old were also positive. The $\mathrm{p}$ value was 0.925 (Table 4).

\begin{tabular}{|l|l|l|l|l|}
\hline Variable & $\begin{array}{l}\text { Ultrasound } \\
\text { negative }\end{array}$ & $\begin{array}{l}\text { Ultrasound } \\
\text { positive }\end{array}$ & P value \\
\hline
\end{tabular}


Citation: Swe M, Subramanium R, Ismail S, Benjamin B (2018) Detection of Non-Traumatic Knee Effusion among Asymptomatic Individual with Different type of Lifestyle and Selected Sociodemographic Factors Using Fluid Shift Test and Ultrasonography. J Arthritis 7: 270. doi: $10.4172 / 2167-7921.1000270$

Page 4 of 5

\begin{tabular}{|c|c|c|c|c|}
\hline & & $\begin{array}{l}\text { Number (\%) } \\
53 \text { (53.5) }\end{array}$ & $\begin{array}{l}\text { Number (\%) } \\
46 \text { (46.5) }\end{array}$ & \\
\hline \multirow[t]{3}{*}{1} & \multicolumn{4}{|l|}{ Age group } \\
\hline & $<25$ years old & 27 (54.0\%) & $23(46.0 \%)$ & \multirow[t]{2}{*}{0.925} \\
\hline & $\geq 25$ & 26 (53.1\%) & 23 (46.9\%) & \\
\hline \multirow[t]{3}{*}{2} & \multicolumn{4}{|l|}{ Gender } \\
\hline & Male & 28 (51.9\%) & 26 (48.1\%) & \multirow[t]{2}{*}{0.713} \\
\hline & Female & 25 (55.6\%) & 20 (44.4\%) & \\
\hline \multirow[t]{3}{*}{3} & \multicolumn{4}{|l|}{ Status } \\
\hline & Staff & $22(47.8 \%)$ & 24 (52.2\%) & \multirow[t]{2}{*}{0.289} \\
\hline & Student & 31 (58.5\%) & 22 (41.5\%) & \\
\hline \multirow[t]{3}{*}{4} & \multicolumn{4}{|l|}{ Lifestyle } \\
\hline & Not active & 15 (55.6\%) & 12 (44.4\%) & \multirow[t]{2}{*}{0.805} \\
\hline & Active & 38 (52.8\%) & 34 (47.2\%) & \\
\hline \multirow[t]{3}{*}{5} & \multicolumn{4}{|l|}{ BMI category } \\
\hline & $<25$ & 35 (58.3\%) & 25 (41.7\%) & \multirow[t]{2}{*}{0.235} \\
\hline & $\geq 25$ & 18 (46.2\%) & $21(53.8 \%)$ & \\
\hline
\end{tabular}

Table 4: The association between demographic variables and ultrasound for knee effusion.

$59.3 \%$ of male were positive whereas only $46.7 \%$ of female were positive for fluid shift test (Table 3).

$48.1 \%$ of male were positive for fluid by ultrasound whereas $44.4 \%$ of female were positive. There was not much difference (Table 4).

$73.6 \%$ students were positive compare to $30.4 \%$ staffs were positive for fluid shift test (Table 3).

$41.5 \%$ students were positive for fluid by ultrasound compare to staffs $52.2 \%$ were positive. There was small difference (Table 4 ).

$61.1 \%$ of respondents who practice active lifestyle were positive for fluid shift test and only $33.3 \%$ of not active respondents were positive (Table 3).

$47.2 \%$ of respondents who practice active lifestyle were positive for fluid by ultrasound and only $44.4 \%$ of not active respondents were positive (Table 4).

$60 \%$ of respondent with BMI less than 25 were positive and only $43.6 \%$ of BMI more than 25 were positive for fluid shift test (Table 3 ).

$41.7 \%$ of respondent with BMI less than 25 were positive for fluid by ultrasound and $53.8 \%$ of respondents with BMI more than 25 were positive (Table 4).

Positive rates of fluid shift test was higher than the positive rates by ultrasound. It is the obvious sign for diagnosis of grade 1, 2 and 3 fluid shift test. Most of the respondents with positive fluid shift test had "TRACE" grade which was very subtle to be noticed and it might lead to over diagnosis. Although inter-rater reliability was $79.25 \%$, higher score of surgeon one was used for calculation. Therefore positive rates for fluid shift test became higher. Only the respondents diagnosed as

fluid shift test was positive by both surgeons were included in calculation the positive rates by fluid shift test and by ultrasound would not be different.

\section{Discussion}

In this study it was noticed that nearly half of the respondents had asymptomatic knee effusion. The presence of increased fluid in the knee confirmed by ultrasound scan showed that respondents who practice active lifestyle and respondents with BMI more than 25 had slightly more prevalence than non-active respondents and respondents with BMI less than 25 respectively (Tables 3 and 4). Although it was not statistically significant, active life style and increased BMI could be one of the causes for increased prevalence of knee effusion.

Students were major portion of active respondents and they were posted to clinical wards to clerk history and did the physical examination on in-patients. They also needed to follow the ward round teaching by consultants, needed to observe and assist the clinical procedures practically. They were engaged with one or two clinical bed side teaching per day which at least lasted for two hours. All these activities in a day needed standing and walking and it might predispose to the increased prevalence of knee effusion which is an early sign of osteoarthritis of knee.

Xia Wang et al. state that although knee effusion-synovitis is not static in elderly, it is predictive of some structural abnormalities in the joint suggesting a potential role in early osteoarthritis changes [1]. From that finding a hypothesis can be assumed that a higher prevalence of knee effusion in active life style groups may predispose to the early onset of osteoarthritis in the later life.

There was no influence on the prevalence of knee effusion by age (under 30) and sex in our research.

\section{Disadvantages}

1. Criteria to include the respondents in active groups relied on the answers by respondents. The results will be more obvious if the respondents with obvious over activity were chosen such as promoters at shopping mall who needed to stand for 12 hours per day.

2. The positive fluid shift test must be assumed as positive only when both Orthopaedic surgeons diagnosed as positive. Higher score should not be assumed as positive.

\section{Suggestion and Conclusion}

To reduce the incidence of osteoarthritis in later life especially for medical students, teaching style modification was suggested such as the demonstration of clinical examination method only should be done at the bed side of patient. Listening the history and discussion for management should be done at seminar room. So as the time around the patient which may cause inconvenience to the patient could be reduced as well.

The finding indicated that five-point scale grading method of fluid shift test for detection of minimal amount of fluid in the knee was a reliable and sensitive test. This test is useful to assess the progress and retrogress of a patient under conservative treatment. Gradual reduction in grade of effusion indicates regression of disease and increased in grade indicates current treatment regime is inadequate. For example, when the grading became severe, attending doctor must think about to change the management plan such as "adding of 
Citation: Swe M, Subramanium R, Ismail S, Benjamin B (2018) Detection of Non-Traumatic Knee Effusion among Asymptomatic Individual with Different type of Lifestyle and Selected Sociodemographic Factors Using Fluid Shift Test and Ultrasonography. J Arthritis 7: 270. doi: 10.4172/2167-7921.1000270

Page 5 of 5

NSAID in treatment", "change in antibiotics used", "aspiration" or "arthrotomy and wash out" etc.

In this study most of the students as well as some clerical staffs with any type of exercise activities were categorized as active persons and remaining were assumed as sedentary persons. Further studies were necessary including participants with most active life style such as promoters at shopping mall who needed to stand for 12 hours comparing clerical staff from some office in the same age group to obtain better and more significant results.

It is necessary to do a long term follow up for early onset osteoarthritis on those participants with positive test results.

\section{Conflict of Interest}

There was no conflict of interest.

\section{Acknowledgement}

This is a short term research grant sponsored by UniKl RCMP.

\section{References}

1. Wang X, Blizzard L, Jin X, Chen Z, Zhu Z, et al. (2016) Quantitative Assessment of Knee Effusion-Synovitis in Older Adults: Association with knee structural abnormalities. Arthritis Rheumatol 68: 837-844.

2. Hong BY, Lee JI, Kim HW, Cho YR, Lim SH, et al. (2011) Detectable threshold of knee effusion by ultrasonography in osteoarthritis patient. Am J Phys Med Rehabil 90: 112-118.
3. Orthopaedics One Articles, orthopaedic knowledge network.

4. Johnson MW (2000) Acute knee effusions: a systematic approach to diagnosis. Am Fam Physician 61: 2391-2400.

5. Blewis ME, Nugent-Derfus GE, Schmidt TA, Schumacher BL, Sah RL (2007) A model of synovial fluid lubricant composition in normal and injured joints. Eur Cell Mater 13: 26-39.

6. Bertram KL, Krawetz RJ (2012) Osmolarity regulates chondrogenic differentiation potential of synovial fluid derived mesenchymal progenitor cells. Biochem Biophys Res Commun 422: 455-461.

7. Lee K (2011) Young people get osteoarthritis too. The Straits Times.

8. Sturgill LP, Snyder-Mackler L, Manal TJ, Axe MJ (2009) Interrater Reliability of a Clinical Scale to assess Knee Joint Effusion. J Orthop Sports Phys Ther 39: 845-849.

9. Hirsch G, O'Neill T, Kitas G, Klocke R (2012) Distribution of effusion in knee arthritis as measured by high-resolution ultrasound. Clin Rheumatol 31: 1243-1246.

10. Hong BY, Lim SH, Cho YR, Kim HW, Ko YJ, et al. (2010) Detection of knee effusion by ultrasonography. Am J Phys Med Rehabil 89: 715-721.

11. Backhaus M, Burmester GR, Gerber T, Grassi W, Machold KP, et al. (2001) Guidelines for musculoskeletal ultrasound in rheumatology. Ann Rheum Dis 60: 641-649.

12. Cibere J, Bellamy N, Thorne A, Esdaile JM, Mc Gorm KJ, et al. (2004) Reliability of the knee examination in osteoarthritis: effect of standardization. Arthritis Rheum 50: 458e68.

13. Magee DJ (1997) Orthopedic Physical Assessment. (3rd edn), Saunders Company, Philadelphia. 